\title{
The effect of maternal anthropometric characteristics and social factors on gestational age and birth weight in Sudanese newborn infants
}

\author{
Eltahir M Elshibly ${ }^{1}$ and Gerd Schmalisch*2
}

Address: ${ }^{1}$ Departments of Paediatrics and Child Health, University of Khartoum, Sudan and ${ }^{2}$ Clinic of Neonatology (Campus Charité Mitte), Universitätsmedizin Berlin, Germany

Email: Eltahir M Elshibly - elshibly@hotmail.com; Gerd Schmalisch* - gerd.schmalisch@charite.de

* Corresponding author

Published: 18 July 2008

BMC Public Health 2008, 8:244 doi: I0.1 186/I47/-2458-8-244
Received: 2 October 2007

Accepted: 18 July 2008

This article is available from: http://www.biomedcentral.com/I47I-2458/8/244

(C) 2008 Elshibly and Schmalisch; licensee BioMed Central Ltd.

This is an Open Access article distributed under the terms of the Creative Commons Attribution License (http://creativecommons.org/licenses/by/2.0), which permits unrestricted use, distribution, and reproduction in any medium, provided the original work is properly cited.

\begin{abstract}
Background: In Africa low birth weight (LBW) $(<2500 \mathrm{~g})$, is the strongest determinant of infant morbidity and mortality. The aim of this study was to quantify the effect of maternal anthropometry, education and socio-economic status on gestational age and birth weight.

Methods: In 1000 Sudanese mothers with singleton births, anthropometric measurements (weight, height, mid-arm circumference) and newborn birth weight were taken within 24 hours of delivery. Furthermore, maternal education and socio-economic status were recorded. The effect of these maternal variables on gestational age and birth weight was investigated by receiver operating characteristic (ROC) curves and by multivariate logistic regression analysis.
\end{abstract}

Results: Although maternal height was significantly correlated $(p=0.002)$ with gestational age, we did not find maternal characteristics of value in determining the risk for preterm birth. Birth order was the strongest determinant of birth weight compared to other maternal characteristics. The LBW rate of first born babies of $12.2 \%$ was nearly twice that of infants of multiparous mothers. Maternal age and all maternal anthropometric measurements were positively correlated $(p<0.00 \mathrm{I})$ with birth weight. A maternal height of $<156 \mathrm{~cm}$, a maternal weight of $<66 \mathrm{~kg}$, a maternal mid arm circumference of $<27 \mathrm{~cm}$ and years of education of $\leq 8$ years were found to increase the relative risk of LBW but this was statistically significant only in the case of maternal height. Maternal age and BMI had no statistically significant effect on determining the risk for LBW. The social class did not affect the birth weight, while the number of years of education was positively correlated with birth weight $(p=0.01)$. The LBW rate decreased from $9.2 \%$ for $\leq 8$ years of education to $6.0 \%$ for $>12$ years of education.

Conclusion: Birth order and maternal height were found to be the most important maternal parameters which influences birth weight and the risk for LBW. The duration of maternal education and not social class was found to significantly affect the risk for LBW. 


\section{Background}

There is a large body of literature showing that the world wide problem of low birth weight (LBW), i.e. infants weighing $<2500 \mathrm{~g}$, is among the strongest determinants of infant mortality and morbidity. While in industrialized countries the majority of LBW infants do well, thanks to the advances of modern obstetric and neonatal care [1] the chances for intact survival of LBW infants is much lower in African and other developing countries due to inadequate or limited medical care including proper antenatal care $[2,3]$.

Beside biological factors like gestational age (GA), maternal weight and height [4], life style factors such as dietary habits, tobacco, alcohol or caffeine consumption [5] can influence birth weight. Furthermore there are sociodemographic and socio-economic factors that are known to affect birth weight. An example is the work by Wasunna et al. [6] who found that maternal education and household income were important factors affecting birth weight.

In Africa there are much higher percentages of women with low education, poverty and poor nutritional status who are therefore at increased risk of adverse reproductive outcomes including LBW and preterm birth. The identification during pregnancy of such mothers is therefore important in order to determine the level of care and priorities for referral to centres where reasonable obstetric and neonatal care are available. Therefore the aim of this study was to investigate the influence of parity, maternal anthropometry, education and socio-economic status on gestational age and birth weight in a sample of mothers and infants from an inner urban area of Khartoum, Sudan. No such comprehensive study was performed before in Sudan.

\section{Methods \\ Patients}

The study was conducted during a one year period and anthropometric measurements were taken from 1000 mothers and their newborns in the Soba University Hospital in Khartoum, Sudan. The mothers were recruited from a large inner urban area of Khartoum with wide differences in the socio-economic status. The three social classes (low, middle, high) were determined by the area of residence. In this study only mothers who were sure of the last date of their menstrual period were included in the study. Mothers who were not sure of their dates or who had multiple pregnancy or had their pregnancy complicated by diabetes mellitus were not included in the study.

The study was approved by the Department of Paediatrics of the University of Khartoum and consent was obtained from the mothers.

\section{Protocol}

In order to exclude inter-observer variation the measurements were taken within 24 hours of birth by one investigator (EME) in the postnatal wards. Maternal anthropometry included mother weight, height and mid arm circumferences. Mothers weight was measured by a standard scale to the nearest 100 grams. The mothers' height was measured with a standard scale for height to the nearest millimeter and the maternal mid arm circumference was measured by an inelastic tape to the nearest millimeter. Babies' weight was measured by a standard scale (Atom Medical, Tokyo, Japan) to the nearest 10 grams, The gestational age was calculated from the last menstrual period in completed weeks of gestation.

\section{Statistics}

Means and standard deviations (SD) were calculated for all maternal anthropometric parameters, gestational age and birth weight. The relationship between maternal anthropometric parameters, gestational age and birth weight was investigated by correlation analysis. Receiver operating characteristic curves (ROC) were drawn to determine optimal cut-off values of the maternal anthropometric parameters that can point to the relative risk for LBW. The optimal cut-off points are defined by the highest numbers of correct classifications considering the LBW rate. The $95 \%$ confidence intervals of the area under the normalized ROC curve (AUC) were calculated as described by Hanley and McNeil [7]. Analysis of variance (ANOVA) was used to investigate the effect of education and social class on gestational age and birth weight. A multivariate logistic regression analysis with backward selection to identify significant influencing factors was performed to investigate the effect of maternal characteristics on preterm birth and LBW. Statistical analysis was performed using the software MEDCALC (Version 9.1.0.1, MedCalc Software, Mariakerke Belgium) and Statgraphics Centurion (Version 15, Stat Point Inc., Herndon, Virginia, USA). Statistical significance was defined as a $\mathrm{p}$ value $<0.05$.

\section{Results \\ Characteristics of the mothers and their newborns}

Maternal age, anthropometric measurements (body weight, height and mid arm circumference), number of years of education and social status of 1000 Sudanese women and the characteristics of their newborns are shown in Table 1 . The number of the first born babies was $370(37 \%)$ and the parity of the $630(63 \%)$ multiparous women ranged from 2 to 14 . Most mothers (64.4\%) belonged to low social class and a considerable number of women $(38.0 \%)$ had an education $\leq 8$ years. The gestational age (GA) ranged between 28 and 42 complete gestational weeks and the birth weight ranged between 800 and 5100 g. 57 (5.7\%) infants were delivered before 37 
Table I: Age, anthropometric parameters, years of education, social class of the mothers and the anthropometric parameters of their newborns (Presented are means (SD), range and N(\%))

\begin{tabular}{|c|c|c|}
\hline & Mean (SD) or N(\%) & Range \\
\hline \multicolumn{3}{|l|}{ Mothers } \\
\hline Age (years) & $27.0(5.4)$ & 16 to 52 \\
\hline Body weight $(\mathrm{kg})$ & $65.2(13.0)$ & 33.5 to 109.9 \\
\hline Body Height (cm) & $159.6(6.2)$ & 139.5 to 195.5 \\
\hline Mid arm circumference $(\mathrm{cm})$ & $26.9(3.9)$ & 17.0 to 40.9 \\
\hline Body mass index $\left(\mathrm{kg} / \mathrm{m}^{2}\right)$ & $25.5(4.8)$ & I 3.5 to 47.1 \\
\hline Number of years of education & $9.1(4.3)$ & 0 to 19 \\
\hline \multicolumn{3}{|c|}{ Social class } \\
\hline low & $644(64.4 \%)$ & \\
\hline middle & $313(31.3)$ & \\
\hline high & $43(4.3)$ & \\
\hline \multicolumn{3}{|l|}{ Newborns } \\
\hline Gestational age (weeks)) & $39.1(1.8)$ & 28 to 42 \\
\hline Birth weight (g) & $3 \mid 31.7(538.9)$ & 800 to 5100 \\
\hline Boys & $514(51.4 \%)$ & \\
\hline LBW $(<2500 \mathrm{~g})$ & $83(8.3 \%)$ & \\
\hline Preterm infants ( $<37$ weeks) & $57(5.7 \%)$ & \\
\hline
\end{tabular}

completed gestational weeks (preterm infants) and 83 $(8.3 \%)$ infants were of LBW $(<2500 \mathrm{~g})$.

\section{Effect of parity on gestational age and birth weight}

With increasing birth order (parity) birth weight increased significantly ( $\mathrm{p}<0.0001)$ as shown in Table 2. However increasing birth order did not seem to affect gestational age at all. The LBW rate of first born babies of $12.2 \%$ was nearly twice that of infants of multiparous mothers. Fig. 1 illustrates that the birth order is the strongest determinant of the relative risk for LBW compared to all other maternal parameters investigated in this study

\section{Influence of maternal anthropometry on gestational age and birth weight}

The correlation coefficients between maternal quantitative characteristics (age, body weight, height and mid arm circumference), gestational age and birth weight are shown in Table 3. Obviously, among the maternal characteristics maternal height was the only one that was weakly positively correlated with gestational age $(\mathrm{p}=0.002)$.

In contrast to the gestational age all maternal characteristics were significantly positively correlated $(\mathrm{p}<0.001)$ with birth weight. Therefore, ROC curves were drawn and an optimal cut-off point for each parameter was defined as shown in Table 4 . The discriminative power of the maternal characteristics to estimate the risk for LBW was assessed by the area under the curve (AUC). As shown in Table 4 only maternal height and body weight had a statistically significant discriminative ability to distinguish between normal and LBW infants. Sensitivity and specificity of the defined cut-off points are shown in Fig. 1.

Using the cut-off points shown in Table 4 the influence of maternal characteristics on birth weight was investigated by calculation of the relative risk for LBW (Fig. 1). Obviously, if the measurements of maternal characteristics are below the cut off point there is a trend to increase the risk of LBW. However, maternal height was the only anthropometric parameter which was statistically significant. A maternal height $<156 \mathrm{~cm}$ increases the relative risk for LBW about $52 \%$

\section{Effect of education and social class on gestational age and birth weight}

The effect of social class and education on gestational age and birth weight is shown in Table 5 and Table 6, respectively. The social class had no statistically significant effect on gestational age and birth weight, while the number of years of education had a statistically significant effect on birth weight but not on gestational age. With increase in the number of years of education the LBW rate decreases (Fig. 2) but the differences were not statistically significant. Furthermore, Fig. 3 shows that the influence of maternal height is distinctly greater than the effect of years of education in determining the risk of LBW.

\section{Logistic regression analysis}

Additionally to the univariate analysis the effect of birth order, maternal anthropometry and the years of education on preterm birth and LBW was investigated using a multivariate logistic regression model. The evaluation showed that no statistically significant model could be obtained ( $p=0.163)$ describing the influence of maternal characteristics on the probability of preterm birth $p(G A<37$ weeks).

In contrast to the gestational age a statistically significant model ( $\mathrm{p}=0.0005)$ for the probability of LBW (p (BW $\leq 2500 \mathrm{~g})$ ) was found:

Table 2: Effect of birth order on gestational age and birth weight

\begin{tabular}{|c|c|c|c|c|}
\hline & First birth $(\mathrm{N}=370)$ & Second birth $(N=206)$ & $\geq$ Third birth $(\mathrm{N}=424)$ & $\mathrm{p}$-value \\
\hline Gestational age (weeks) & 39.1 (I.8) & 39.1 (1.7) & $39.0(1.8)$ & $p=0.573$ \\
\hline Birth weight $(\mathrm{g})$ & $3021.6(527.2)$ & $3156.9(497.1)$ & $3215.7(553.0)$ & $p=0.0001$ \\
\hline LBW-rate (\%) & $12.2 \%$ & $5.3 \%$ & $6.4 \%$ & $p=0.003$ \\
\hline
\end{tabular}




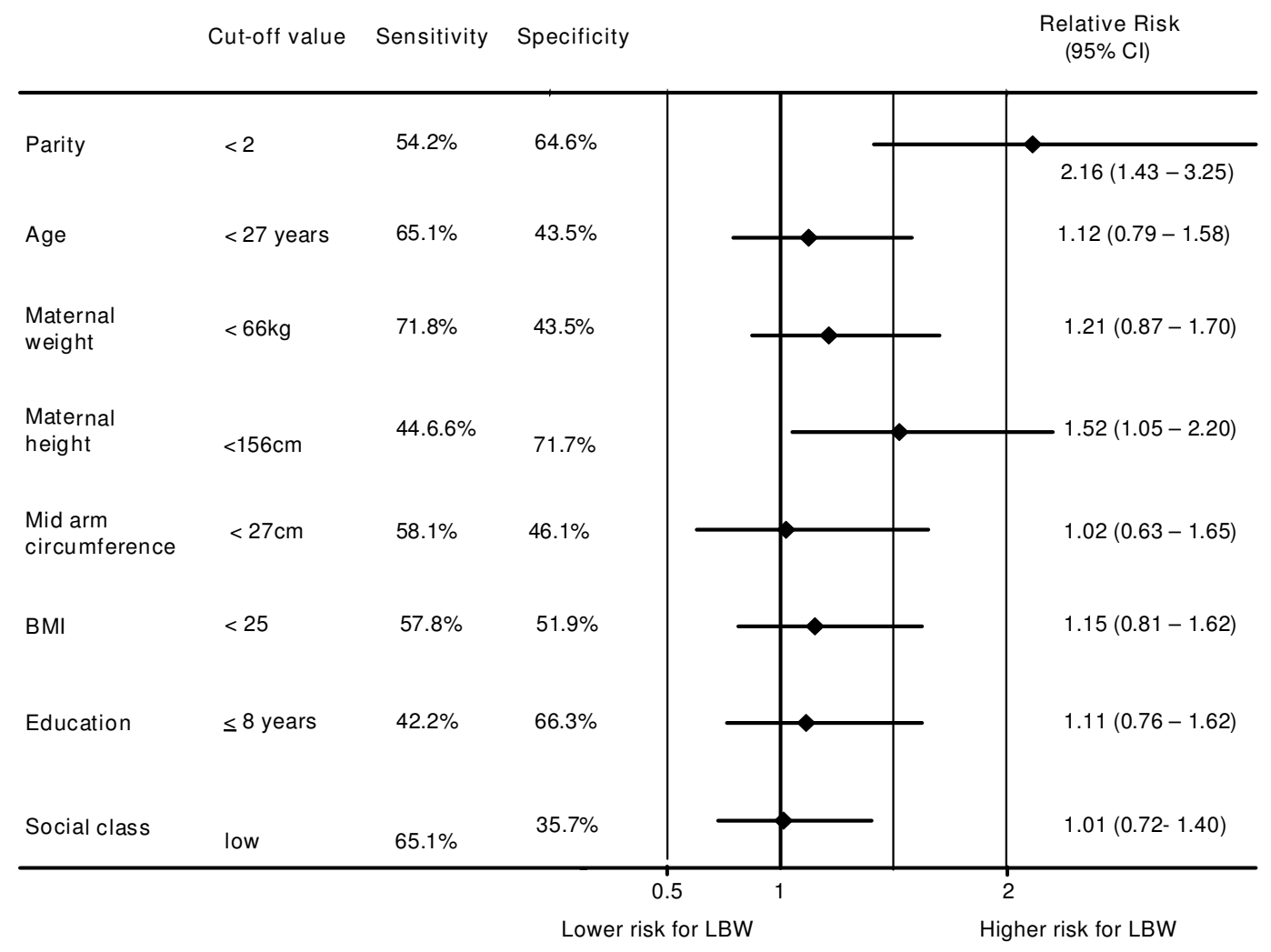

Figure I

Effect of maternal characteristics on the relative risk for LBW.

$\mathrm{p}(\mathrm{BW} \leq 2500 \mathrm{~g})=\frac{1}{1+\mathrm{e}^{-\mathrm{Z}}}$ with

$\mathrm{Z}=16.90-1.303 \cdot \mathrm{PAR}+0.060 \cdot \mathrm{MA}+0.122 \cdot \mathrm{MW}-0.123$

- MH - $0.050 \cdot$ MMAC - $0.153 \cdot$ BMI - $0.0340 \cdot$ YED

Where PAR is the dichotomized parity ( $=0$ for first birth order, $=1$ for birth order $\geq 2$ ), $\mathrm{MA}$ is the maternal age in years, $\mathrm{MW}$ is the maternal weight in $\mathrm{kg}, \mathrm{MH}$ is the maternal height in $\mathrm{cm}, \mathrm{MMAC}$ is the maternal mid arm circumference in $\mathrm{cm}$ and YED is number of years of education. However, some parameters in this model were strongly

Table 3: Pearson correlation coefficients (p-values in brackets) between maternal characteristics (age, anthropometry) and gestational age and birth weight (Statistically significant values are printed in bold)

\begin{tabular}{lll}
\hline Maternal characteristics & Gestational age & Birth weight \\
\hline Age & $-0.029(p=0.355)$ & $\mathbf{0 . 1 0 8}(\mathbf{p}<\mathbf{0 . 0 0 1})$ \\
Body weight & $0.040(p=0.211)$ & $\mathbf{0 . 1 6 5}(\mathbf{p}<\mathbf{0 . 0 0 1})$ \\
Body Height & $\mathbf{0 . 1 0 1 ( p = 0 . 0 0 2 )}$ & $\mathbf{0 . 1 4 9}(\mathbf{p}<\mathbf{0 . 0 0 1})$ \\
Mid arm circumference & $0.074(p=0.098)$ & $\mathbf{0 . 1 7 1}(\mathbf{p}<\mathbf{0 . 0 0 1})$ \\
Body mass index & $-0.003(p=0.938)$ & $\mathbf{0 . 1 1 2 ( p < 0 . 0 0 1 )}$
\end{tabular}

correlated with each other (e.g., MW and BMI with $\mathrm{r}=$ 0.921 ) so that they did not give additional information and were therefore eliminated by the backward selection method. The backward selection of this model showed that the only statistically significant predictors for LBW were parity $(p=0.009)$ and maternal height $(p=0.006)$ and the logistic regression model can be simplified to:

$$
\begin{aligned}
& \mathrm{p}(\mathrm{BW} \leq 2500 \mathrm{~g})=\frac{1}{1+\mathrm{e}^{-\mathrm{z}}} \text { with } \\
& \mathrm{z}=6.434-0.625 \cdot \mathrm{PAR}-0.054 \cdot \mathrm{MH} .
\end{aligned}
$$

This model shows that the probability of LBW is mainly influenced by birth order and maternal height and this result agrees well with the results of the univariate evaluation shown in Fig. 1.

\section{Discussion}

The status of the mother nutrition and socio-economic variables have long been known to influence the reproductive performance and outcome and the condition of the infant at birth. 
Table 4: ROC analysis of maternal age and maternal anthropometric parameters in the estimation of the risk for LBW.

\begin{tabular}{lccc}
\hline Parameter & Optimal cut-off point & AUC with 95\%Cl & $\mathrm{P}$-value \\
\hline Maternal age $($ years $)$ & 27 & $0.536(0.504$ to 0.567$)$ & 0.268 \\
Maternal height $(\mathrm{cm})$ & 156 & $0.591(0.560$ to 0.622$)$ & $\mathbf{0 . 0 0 3}$ \\
Maternal weight $(\mathrm{kg})$ & 66 & $0.567(0.536$ to 0.599$)$ & $\mathbf{0 . 0 3 7}$ \\
Maternal mid arm circumference $(\mathrm{cm})$ & 27 & $0.542(0.497$ to 0.586$)$ & 0.351 \\
Body mass index $\left(\mathrm{kg} / \mathrm{m}^{2}\right)$ & 25 & $0.535(0.504$ to 0.567$)$ & 0.276 \\
\hline
\end{tabular}

The p-value calculated according Hanley and McNeil [7] indicates whether the area under the normalized ROC curve (AUC) is statistically different from 0.5 (no discrimination). If the $p$ value is statistically not significant then there is no evidence that the parameter has the ability to influence the risk for LBW.

Table 5: Effect of social class on gestational age and birth weight tested by ANOVA

\begin{tabular}{|c|c|c|c|c|}
\hline & $\begin{array}{l}\text { High social class } \\
\qquad(N=43)\end{array}$ & $\begin{array}{l}\text { Middle social class } \\
\quad(\mathrm{N}=3 \mid 3)\end{array}$ & $\begin{array}{l}\text { Low social class } \\
\qquad(\mathrm{N}=644)\end{array}$ & $\mathrm{P}$-value \\
\hline Gestational age (weeks) & 39.1 (1.2) & 39.1 (1.9) & $39.0(1.7)$ & $p=0.777$ \\
\hline Birth weight (g) & 3208.1 (590.7) & $3164.9(541.9)$ & $3110.5(533.5)$ & $p=0.218$ \\
\hline
\end{tabular}

In our study using both univariate analysis and confirming by multivariate logistic regression model, we could demonstrate that birth order, maternal anthropometric characteristics and education are of value in estimating the increased risk for LBW. However we could not demonstrate that maternal characteristics can predict the increased risk for preterm delivery as already shown by Voigt et al. [4] et al in Germany and Honest et al. [8] in Great Britain. Beside antenatal care and woman's health status, birth order was found to be one of the major factors affecting birth weight [9], and several studies have shown that birth weight increases with birth order [1012]. Hirve et al. [13] in India found a 1.3 higher relative risk for LBW in primipara and in Africa Lawoyin [14] found that first born babies had a 3.1 fold higher mortality risk. In our study primiparity was associated with an increased relative risk for LBW of 2.16, and that was distinctly higher when compared to the relative risk for LBW of other maternal characteristics (Fig. 1).

Maternal height was the second most important parameter which influences the risk for LBW in our mothers. Our cut off point of $156 \mathrm{~cm}$ agrees well with investigators in Bangladesh [15] who also found that maternal height below $155 \mathrm{~cm}$ increases the risk for child death. This con- firms the value of maternal height as a predictor of childhood morbidity and mortality. Zhang et al. [16] suggested that the slower fetal growth due to short maternal stature appears to be physiologic. Veena et al. [17] pointed out that the size of the infant at birth is influenced by paternal rather than maternal height while Voigt et al. [4] found that the influence of paternal characteristics on infant size at birth is negligible.

The lower predictive value of maternal weight measured at delivery in our study could be due to the high individual differences in the changes that occur in the body weight during pregnancy. In contrast maternal height is not liable to such changes as a result of pregnancy.

The duration of maternal education and not maternal social class was found to significantly affect the risk for LBW. Karim et al. [18] found that birth weight increases with higher maternal education while in Germany [19] women with the lowest education had significantly elevated risk for small for gestational age newborns (SGA).

Our study confirms the usefulness of anthropometric measurements in identifying mothers at high risk of delivering LBW infants as found by other workers $[20,21]$.

Table 6: Effect of the number of years of education on gestational age and birth weight (ANOVA, statistically significant p-values are printed in bold)

\begin{tabular}{lllll}
\hline & $\begin{array}{l}0-8 \text { years } \\
(\mathrm{N}=380)\end{array}$ & $\begin{array}{l}9-12 \text { years } \\
(\mathrm{N}=487)\end{array}$ & $\begin{array}{l}>12 \text { years } \\
(\mathrm{N}=133)\end{array}$ & $\mathrm{P}$-value \\
\hline $\begin{array}{l}\text { Gestational age (weeks) } \\
\text { Birth weight (g) }\end{array}$ & $\begin{array}{l}39.1(1.9) \\
3078.2(552.0)\end{array}$ & $\begin{array}{l}39.0(1.8) \\
3139.3(520.1)\end{array}$ & $\begin{array}{l}39.2(1.3) \\
3257.1(550.8)\end{array}$ & $\mathrm{P}=0.505$ \\
\hline
\end{tabular}




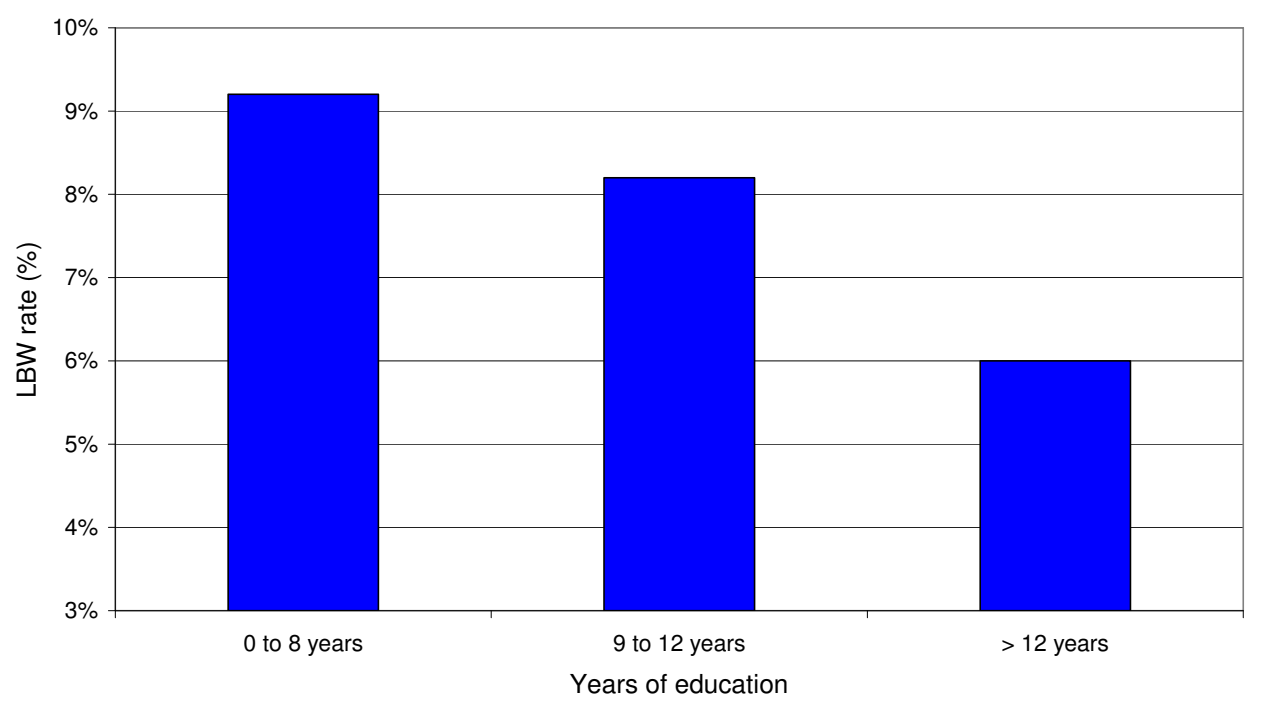

Figure 2

Low birth weight rate in relation to number of years of education.

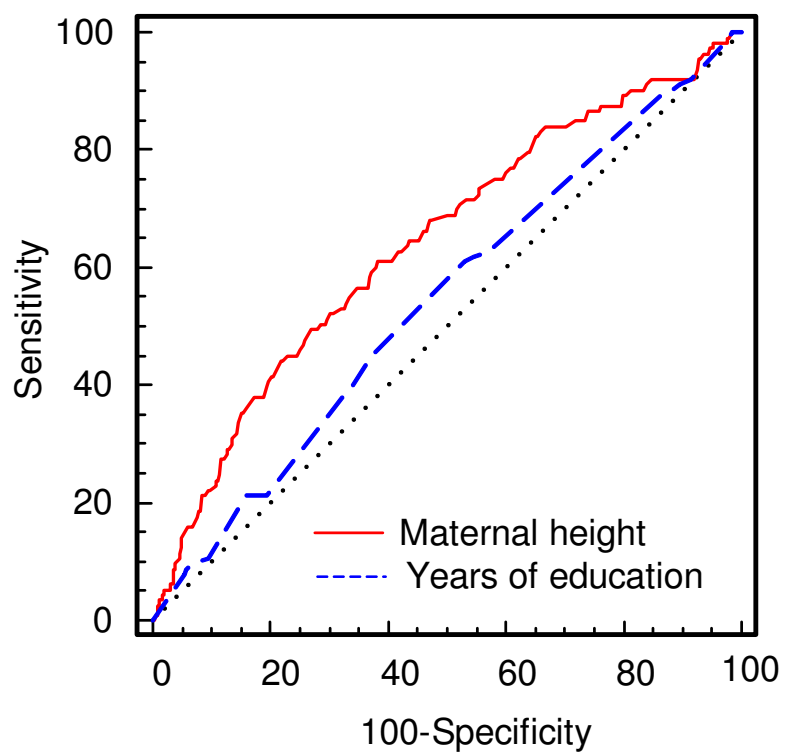

Figure 3

Comparison of the ROC curves of the maternal height and the years of education to estimate the risk for LBW. The dotted diagonal line represents "no discrimination". AUC of education is distinctly lower compared to the AUC of maternal height.
However we would like to point to the limitation of using anthropometric measurements taken before pregnancy to estimate the risk for LBW, as such measurements can seldom be taken in Africa, where women commonly present to health facilities only when they are advanced in pregnancy.

\section{Conclusion}

In our study birth order was found to be the major factor affecting LBW rate. The influence of the other maternal characteristics is distinctly lower. Nevertheless women with a height of $<156 \mathrm{~cm}$ and education of $\leq 8$ years had a LBW rate of $13.7 \%$. This means that almost one seventh of such mothers will have low birth weight babies. Therefore, we recommend that policy makers should make more emphasis on education as it imparts knowledge and thus modify dietary habits and quality of food consumed. This will lead to a better nutritional status in adolescent girls, resulting in lower rates of LBW and hence great reduction in infant morbidity and mortality.

\section{Abbreviations}

AUC: Area under the ROC curve; CI: Confidence interval: GA: Gestational age; LBW: Low birth weight; ROC: Receiver operatic characteristic; SD: Standard deviation.

\section{Competing interests}

The authors declare that they have no competing interests. 


\section{Authors' contributions}

EME and GS had primary responsibility for writing of the manuscript. EME carried out all anthropometric measurements and GS performed statistical analysis. All authors read and approved the final manuscript.

\section{Acknowledgements}

We acknowledge the kind help and encouragement we received from the nursing, medical and administrative staff of Soba university hospital.

\section{References}

I. Grimmer I, Buhrer C, Dudenhausen JW, Stroux A, Reiher H, Halle H, Obladen M: Preconceptional factors associated with very low birthweight delivery in East and West Berlin: a case control study. BMC Public Health 2002, 2:10.

2. Simiyu DE: Neonatal septicaemia in low birth weight infants at Kenyatta National Hospital, Nairobi. East Afr Med J 2005, 82:148-I52.

3. Elshibly EM, Schmalisch G: Correlation between anthropometric measures and birthweight of infants: value in measuring actual birthweight. Am J Perinatol 2008, 25:135-139.

4. Voigt $M$, Heineck $G$, Hesse V: The relationship between maternal characteristics, birth weight and pre-term delivery: evidence from Germany at the end of the 20th century. Econ Hum Biol 2004, 2:265-280.

5. Nordentoft M, Lou HC, Hansen D, Nim J, Pryds O, Rubin P, Hemmingsen R: Intrauterine growth retardation and premature delivery: the influence of maternal smoking and psychosocial factors. Am J Public Health 1996, 86:347-354.

6. Wasunna A, Mohammed K: Low birthweight babies: sociodemographic and obstetric characteristics of adolescent mothers at Kenyatta National Hospital, Nairobi. East Afr Med J 2002, 79:543-546.

7. Hanley JA, McNeil BJ: The meaning and use of the area under a receiver operating characteristic (ROC) curve. Radiology 1982, 143:29-36.

8. Honest H, Bachmann LM, Ngai C, Gupta JK, Kleijnen J, Khan KS: The accuracy of maternal anthropometry measurements as predictor for spontaneous preterm birth--a systematic review. Eur J Obstet Gynecol Reprod Biol 2005, I I 9: I I-20.

9. Celik Y, Younis MZ: Effects of antenatal care services on birthweight: importance of model specification and empirical procedure used in estimating the marginal productivity of health inputs. J Med Syst 2007, 3 I: 197-204.

10. Maruoka K, Yagi M, Akazawa K, Kinukawa N, Ueda K, Nose Y: Risk factors for low birthweight in Japanese infants. Acta Paediatr 1998, 87:304-309.

II. Seidman DS, Ever-Hadani P, Stevenson DK, Slater PE, Harlap S, Gale R: Birth order and birth weight reexamined. Obstet Gynecol 1988, 72:158-162.

12. Peters TJ, Golding J, Butler NR, Fryer JG, Lawrence CJ, Chamberlain GV: Plus ca change: predictors of birthweight in two national studies. Br J Obstet Gynaecol 1983, 90: 1040-1045.

13. Hirve SS, Ganatra BR: Determinants of low birth weight: a community based prospective cohort study. Indian Pediatr 1994, 3I:1221-1225

14. Lawoyin TO: Infant and maternal deaths in rural south west Nigeria: a prospective study. Afr J Med Med Sci 2007, 36:235-24I.

15. Baqui $A H$, Arifeen SE, Amin S, Black RE: Levels and correlates of maternal nutritional status in urban Bangladesh. Eur J Clin Nutr 1994, 48:349-357.

16. Zhang X, Cnattingius S, Platt RW, Joseph KS, Kramer MS: Are babies born to short, primiparous, or thin mothers "normally" or "abnormally" small? J Pediatr 2007, I 50:603-7, 607.

17. Veena SR, Kumaran K, Swarnagowri MN, Jayakumar MN, Leary SD, Stein CE, Cox VA, Fall CH: Intergenerational effects on size at birth in South India. Paediatr Perinat Epidemiol 2004, I 8:36I-370.

18. Karim E, Mascie-Taylor CG: The association between birthweight, sociodemographic variables and maternal anthropometry in an urban sample from Dhaka, Bangladesh. Ann Hum Biol 1997, 24:387-40I.

19. Raum E, Arabin B, Schlaud M, Walter U, Schwartz FW: The impact of maternal education on intrauterine growth: a comparison of former West and East Germany. Int I Epidemiol 200I, 30:8I-87.

20. Mohanty C, Prasad R, Srikanth RA, Ghosh JK, Singh TB, Das BK: Maternal anthropometry as predictors of low birth weight. J Trop Pediatr 2006, 52:24-29.

21. Ogbonna C, Woelk GB, Ning Y, Mudzamiri S, Mahomed K, Williams MA: Maternal mid-arm circumference and other anthropometric measures of adiposity in relation to infant birth size among Zimbabwean women. Acta Obstet Gynecol Scand 2007, 86:26-32.

\section{Pre-publication history}

The pre-publication history for this paper can be accessed here:

\section{http://www.biomedcentral.com/1471-2458/8/244/pre} pub
Publish with Bio Med Central and every scientist can read your work free of charge

"BioMed Central will be the most significant development for disseminating the results of biomedical research in our lifetime. "

Sir Paul Nurse, Cancer Research UK

Your research papers will be:

- available free of charge to the entire biomedical community

- peer reviewed and published immediately upon acceptance

- cited in PubMed and archived on PubMed Central

- yours - you keep the copyright
BiolMedcentral 